\title{
Effect of Fragarin on the Cytoplasmic Membrane of the Phytopathogen Clavibacter michiganensis
}

\author{
M. Paula Filippone, Juan C. Diaz-Ricci, Atilio P. Castagnaro, and Ricardo N. Farías \\ Departamento de Bioquímica de la Nutrición, Instituto Superior de Investigaciones Biológicas (Consejo \\ Nacional de Investigaciones Científicas y Técnicas-Universidad Nacional de Tucumán) and Instituto de \\ Química Biológica "Dr. Bernabé Bloj," 4000 San Miguel de Tucumán, Argentina \\ Submitted 27 November 2000; Accepted 20 March 2001.
}

\begin{abstract}
Fragarin, an antibiotic that was isolated and purified from a soluble fraction of strawberry leaves, may be a new type of preformed antimicrobial compound (phytoanticipin). Here, we report that the growth and oxygen consumption of the phytopathogenic bacterium Clavibacter michiganensis were rapidly inhibited after the addition of fragarin to cultures. Also, dissipation of the membrane potential and an increase of cell membrane permeability were observed in the presence of fragarin. The ability of fragarin to dissipate the membrane potential was confirmed with the use of small unilamellar liposomes made with lipids extracted from $C$. michiganensis. Our results suggest that fragarin is able to act at the membrane level, and that this action is correlated with a decrease in cell viability.
\end{abstract}

Additional keywords: biological membrane, preformed antiphytopathogenic compounds.

It has been demonstrated that secondary metabolites have different functions in plants and many are important components of plant-defense mechanisms (Harbone 1991). Two categories of secondary metabolites with antibiotic activity were proposed in accordance to how they are produced: inducible and preformed compounds. Inducible compounds such as phytoalexins are antimicrobials, which are synthesized de novo in response to biotic or abiotic elicitors (Kuc 1995). Preformed compounds such as phytoanticipins, however, can be found in their biologically active form, even in uninjured plants, or as inactive precursors that can be activated by means of specific enzymes (Osbourn 1996). Therefore, the fundamental difference between phytoalexins and phytoanticipins is that the former are involved in an active plant response against a pathogen, whereas phytoanticipins are involved in a passive plant-defense response (Van Etten 1994). Recently, we isolated a $316-\mathrm{kDa}$ amphipathic molecule, fragarin, from a soluble fraction of strawberry leaves. Fragarin shows activity against bacterial and fungal plant pathogens and, according to the biological and chemical features shown by fragarin, we speculate that it may be a new type of phytoanticipin related to secondary metabolites (Filippone et al.

Corresponding author: R. Farias; Telephone: +54 0381424 8921; Fax: +54 0381424 8025; E-mail: farias@unt.edu.ar
1999) and could be involved in the defense of strawberry against pathogen attack. The aim of this work is to obtain insight into the antibiotic activity of fragarin.

The bacterium Clavibacter michiganensis subsp. sepedonicus strain C5 was used in biological assays provided by A. Molina from the Escuela Técnica Superior de Ingenieros Agrónomos (ETSIA) collection, Madrid, Spain. Strawberry (Fragaria ananassa) cultivar Chandler was grown for 20 days in sterilized substrate $(3: 2: 1$ parts of soil-sand-perlite, respectively), at $25^{\circ} \mathrm{C}$ and $70 \%$ relative humidity, with a 16 -h photoperiod. Leaves were collected and frozen immediately in liquid nitrogen. Leaf homogenate was obtained from fresh material that was frozen previously and ground in liquid nitrogen. Fragarin was extracted from leaf powder, as previously reported (Filippone et al. 1999). The purification of fragarin included the direct adsorption of the extract (centrifuged at $16,000 \times g$ for $15 \mathrm{~min}$ ) on $60 \mathrm{ml}$ of a preparative Mega Bond Elut C8 cartridge (Varian, Palo Alto, CA, U.S.A.), followed by washing with water, water-acetonitrile $(50: 50 \mathrm{vol} / \mathrm{vol})$, and acetonitrile. The latter fraction containing fragarin was subjected to fast protein liquid chromatography with a reversephase C1/C8 column $(0.5 \times 10 \mathrm{~cm}$, ProRPC HR 5/10; Amersham Pharmacia Biotech, Piscataway, NJ, U.S.A.) equilibrated with water containing $0.1 \%$ trifluoroacetic acid (TFA). The elution was performed for $30 \mathrm{~min}$ with a linear gradient ( 0 to $100 \%$ ) of water-acetonitrile containing $0.1 \%$ TFA (vol $/ \mathrm{vol}$ ) with an additional $15 \mathrm{~min}$ of $100 \%$ acetonitrile at $0.25 \mathrm{ml}$ per min (detection at $280 \mathrm{~nm})$. Fractions $(0.5 \mathrm{ml})$ were collected and assayed for antibiotic activity with $C$. michiganensis. Active fractions that eluted at $100 \%$ acetonitrile were pooled, lyophilized, dissolved in water, and rechromatographed with a linear gradient of water-acetonitrile (90 to 100\%) and the same column for $15 \mathrm{~min}$. The active fraction eluted as a unique and homogeneous peak at $98 \%$ acetonitrile (Filippone et al. 1999).

Oxygen consumption was measured polarographically with a Gilson oxygraph (Middleton, WI, U.S.A.) equipped with a Clark-type electrode in a closed, stirred glass vessel of 2.0-ml volume at $30^{\circ} \mathrm{C}$. Fragarin $(2.0 \mu \mathrm{M})$ was added to a culture of C. michiganensis growing in Luria-Bertani (LB) medium at $30^{\circ} \mathrm{C}$ during the exponential-phase optical density (OD) at 600 $\mathrm{nm}$ of 0.2 to 0.3 . Aliquots of $2 \mathrm{ml}$ were removed at different times and transferred to an oxymeter cell. Oxygen consumption was recorded on-line. 
Cytoplasmic membrane permeability was determined with potential-sensitive cyanine dye 3,5'-dipropylthiacarbocyanine iodide (diSC3-5) (Wu et al. 1999). This dye partitions between cells and the medium, depending upon the membranepotential gradient. When the gradient is high, the dye penetrates into the cell and quenches its own fluorescence. An increase of the fluorescence resulting from the disruption of the cytoplasmic membrane can be observed after the addition of a membrane-interacting agent (Wu et al. 1999). C. michiganensis was grown in $\mathrm{LB}$ medium at $30^{\circ} \mathrm{C}$ to midexponential phase $\left(\mathrm{OD}_{600}=0.4\right.$ to 0.5$)$. The cells were collected by centrifugation, washed once with $5 \mathrm{mM} \mathrm{Na} N-2$ hydroxyethylpiperazine- $N$-2-ethanesulfonic acid (HEPES; $\mathrm{pH}$ $7.2,5 \mathrm{mM}$ glucose), and resuspended in the same buffer to obtain $\mathrm{OD}_{600}=1.0$. A $100-\mu$ l cell suspension was transferred to a spectrofluorometer cuvette containing $2.0 \mathrm{ml}$ of $5 \mathrm{mM} \mathrm{Na}$ HEPES buffer (pH 7.2, $5 \mathrm{mM}$ glucose, $100 \mathrm{mM} \mathrm{KCl}$ ) to obtain $\mathrm{OD}_{600}=0.05$. After the addition of $0.4 \mu \mathrm{M}$ diSC3-5, the cuvette was incubated at $37^{\circ} \mathrm{C}$ until the dye uptake was maximal (as indicated by a reduction of fluorescence to a stable value, approximately $5 \mathrm{~min}$ ). The desired concentration of fragarin was added to a suspension of diSC3-5-loaded cells,

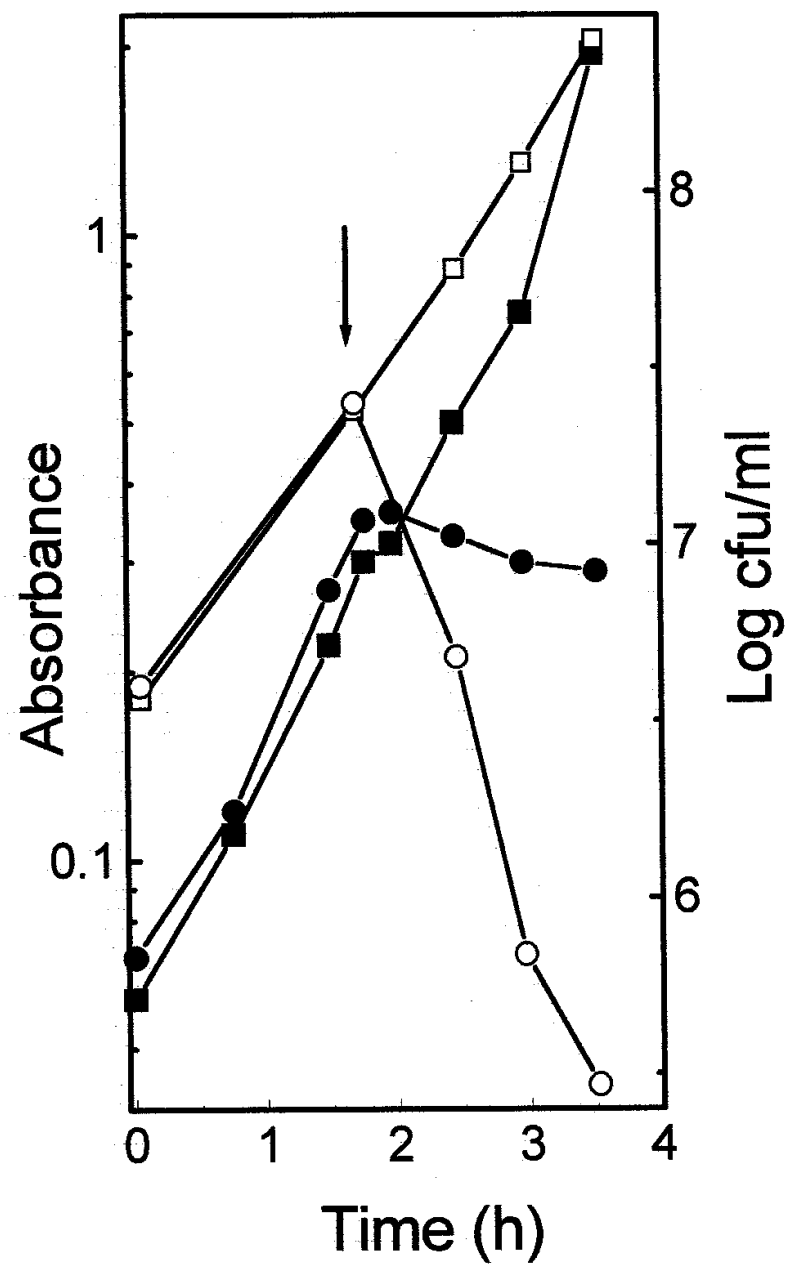

Fig. 1. Effect of $2 \mu \mathrm{M}$ fragarin on the growth of Clavibacter michiganensis. $\mathbf{\square}=$ Optical density (OD) in the absence of fragarin. $\bullet=$ OD in the presence of fragarin. $\square=\mathrm{CFU} / \mathrm{ml}$ in the absence of fragarin. $\bigcirc=$ $\mathrm{CFU} / \mathrm{ml}$ in the presence of fragarin (arrow). and the dye fluorescence increase was recorded at $670 \mathrm{~nm}$ with a RF-5301PC spectrofluorometer, with excitation set at $622 \mathrm{~nm}$ (Shimadzu, Kyoto, Japan). A cuvette containing diSC3-5-loaded cells was used to subtract the background. The effect of the external $\mathrm{KCl}$ concentration on the fluorescence intensity in the presence and absence of valinomycin after the stabilization was determined previously, as indicated by $\mathrm{Wu}$ et al. (1999). The antibiotic valinomycin is a $\mathrm{K}^{+}$selective ionophore that changes the membrane potential. Results indicate that in the presence of $1 \mu \mathrm{M}$ valinomycin, fluorescence reached a maximum of $100 \mathrm{mM} \mathrm{KCl}$ as a result of a $\mathrm{K}^{+}$ concentration equilibrium established between both sides of the cell membrane. In the absence of valinomycin, the fluorescence intensity was not modified by the addition of $100 \mathrm{mM} \mathrm{KCl}$ to the assay buffer. In order to prevent any effects resulting from the movement of potassium ions, an external concentration of $100 \mathrm{mM} \mathrm{KCl}$ was added in all cases to the cell suspension (Wu et al. 1999).

Changes in the membrane potential dissipation were studied in liposome, as indicated by Gao et al. (1991). Lipids were extracted from $C$. michiganensis cells grown previously in LB medium at $30^{\circ} \mathrm{C}$ to midexponential phase $\left(\mathrm{OD}_{600}=0.4\right.$ to 0.5$)$ and purified according to Kates (1986). Appropriate quantities of lipids dried extensively under a nitrogen stream were suspended by vortexing in $1 \mathrm{ml}$ of $50 \mathrm{mM}$ potassium phosphate buffer, $\mathrm{pH}$ 7.0. To obtain small unilamellar phospholipid vesicles, the formed multilamellar liposomes were subjected to sonication for $20 \mathrm{~min}$, with intervals of $15 \mathrm{~s}$ at $5^{\circ} \mathrm{C}$, with a sonicator (Cole-Parmer, Vernon Hills, IL, U.S.A.). Large particles were eliminated by centrifugation at $10,000 \times g$ in a fixed angle rotor centrifuge for $5 \mathrm{~min}$. Potassium-loaded liposomes were diluted 100 -fold in $50 \mathrm{mM}$ sodium phosphate buffer, $\mathrm{pH} 7.0$, and $0.4 \mu \mathrm{M}$ diSC3-5 was added. Afterward, $0.05 \mu \mathrm{M}$ valinomycin was added to generate a membrane potential that was stable for $2 \mathrm{~h}$. The fluorescence intensity was measured, as described above.

Experiments were repeated at least three times under identical experimental conditions and identical outcomes were obtained. Results of representative experiments are shown in the figures of this paper.

In a previous report, it was shown that fragarin is capable of inhibiting the growth of plant-pathogenic bacteria and fungi (Filippone et al. 1999). In the present work, we chose the $C$. michiganensis strain C5 because it proved to be the most fragarin-sensitive bacterium (Filippone et al. 1999). When $2 \mu \mathrm{M}$ fragarin was added to an actively growing culture of C. michiganensis, growth stopped and remained constant. After $2 \mathrm{~h}$, the viable cell counts decreased by three orders of magnitude (Fig. 1). We also observed that the oxygen consumption was inhibited by the addition of fragarin. The respiratory rate of $C$. michiganensis depends upon the cellular concentration in the oxymeter cell (not shown). Under our experimental conditions, the oxygen concentration decreased by approximately $35 \%$ in 10 min (Fig. 2, line a) in control experiments of cultures without fragarin. By contrast, when a culture of C. michiganensis was treated with $2 \mu \mathrm{M}$ fragarin for 5 min, oxygen consumption was abolished totally (Fig. 2, line b). Because respiratory function is dependent upon an intact and functional cytoplasmic membrane, we evaluated the influence of fragarin on the integrity of the cytoplasmic membrane of $C$. michiganensis by the cyanine dye 3,5'-dipropylthiacarbocyanine 
iodide (diSC3-5) method (Wu et al. 1999). After the addition of $0.15 \mu \mathrm{M}$ fragarin to dye-loaded cells, an increase of fluorescence appeared, reaching a maximum within $1 \mathrm{~min}$ (Fig. 3A). As suggested by Wu et al. (1999), this increase in fluorescence correlates with the dissipation of the membrane potential and increased membrane permeability. In parallel experiments, valinomycin was used as a positive control. The fluorescence did not change during the assay time in the absence of fragarin or valinomycin (Fig. 3A). Figure 3B shows the influence of fragarin concentration on the membrane permeability of $C$. michiganensis. This outcome agrees with the $50 \%$ effective concentration values $(0.07 \mu \mathrm{M})$ reported previously (Filippone et al. 1999).

The ability of fragarin to dissipate the membrane potential also was confirmed with small unilamellar liposomes made with lipids extracted from $C$. michiganensis. Figure 4 shows that fluorescence decreased after the addition of valinomycin, indicating membrane-potential generation in liposomes $(\Delta \psi$, interior negative). Also shown in Figure 4 is the gradual fluorescence increase observed upon fragarin addition, indicating that the induced potential is dissipated. The addition of fragarin to liposomes that were not treated previously with valinomycin had no effect (not shown). In these experiments, the antibiotic nigericin, known for its ability to disrupt membrane potential (Rottenberg and Scarpa 1974), was used as a positive control. When potassium-loaded liposomes were diluted 100 -fold in $50 \mathrm{mM}$ potassium phosphate instead of 50 $\mathrm{mM}$ sodium phosphate, no effect of fragarin was observed. In this liposome preparation, valinomycin is not able to generate a potential difference (data not shown).

In summary, the present paper demonstrates that fragarin is able to alter permeability and disrupt membrane function, resulting in the dissipation of membrane potential in intact

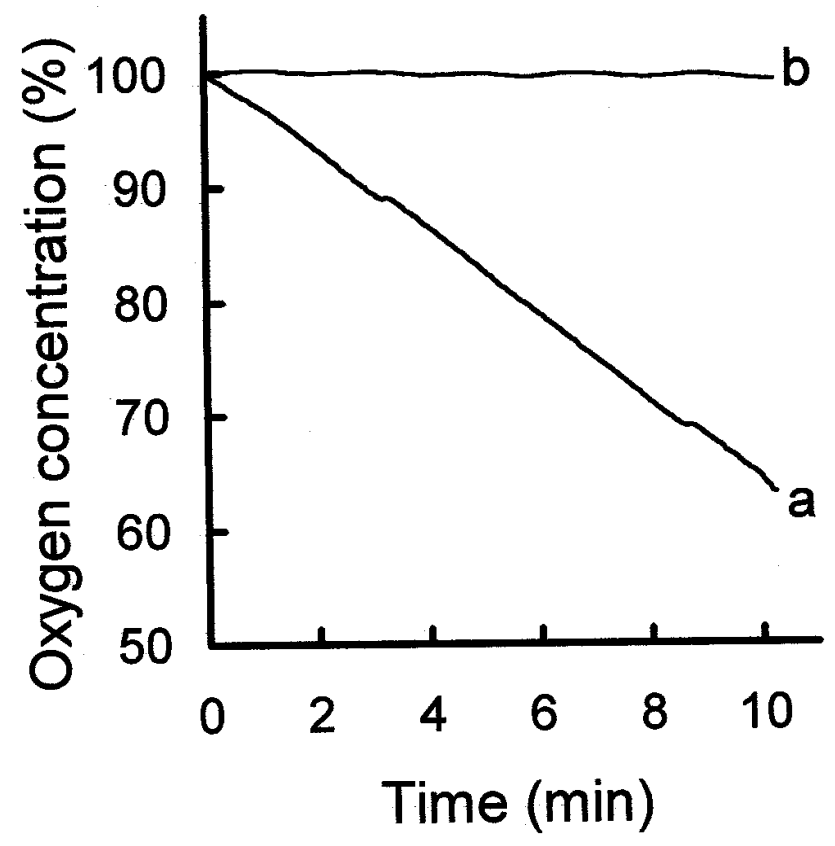

Fig. 2. Effect of $2.0 \mu \mathrm{M}$ fragarin on the oxygen consumption of a Clavibacter michiganensis culture growing in Luria-Bertani medium. Oxygen concentration of a control culture (a) and a culture treated with fragarin for $5 \min (b)$. cells of the sensitive $C$. michiganensis strain used. Furthermore, the ability of fragarin to dissipate membrane potential was further confirmed with the use of liposomes (Fig. 4). The immediate inhibition of oxygen consumption (Fig. 2) and the immediate dissipation of membrane potential (an increase of fluorescence) (Fig. 3) suggest that the fragarin
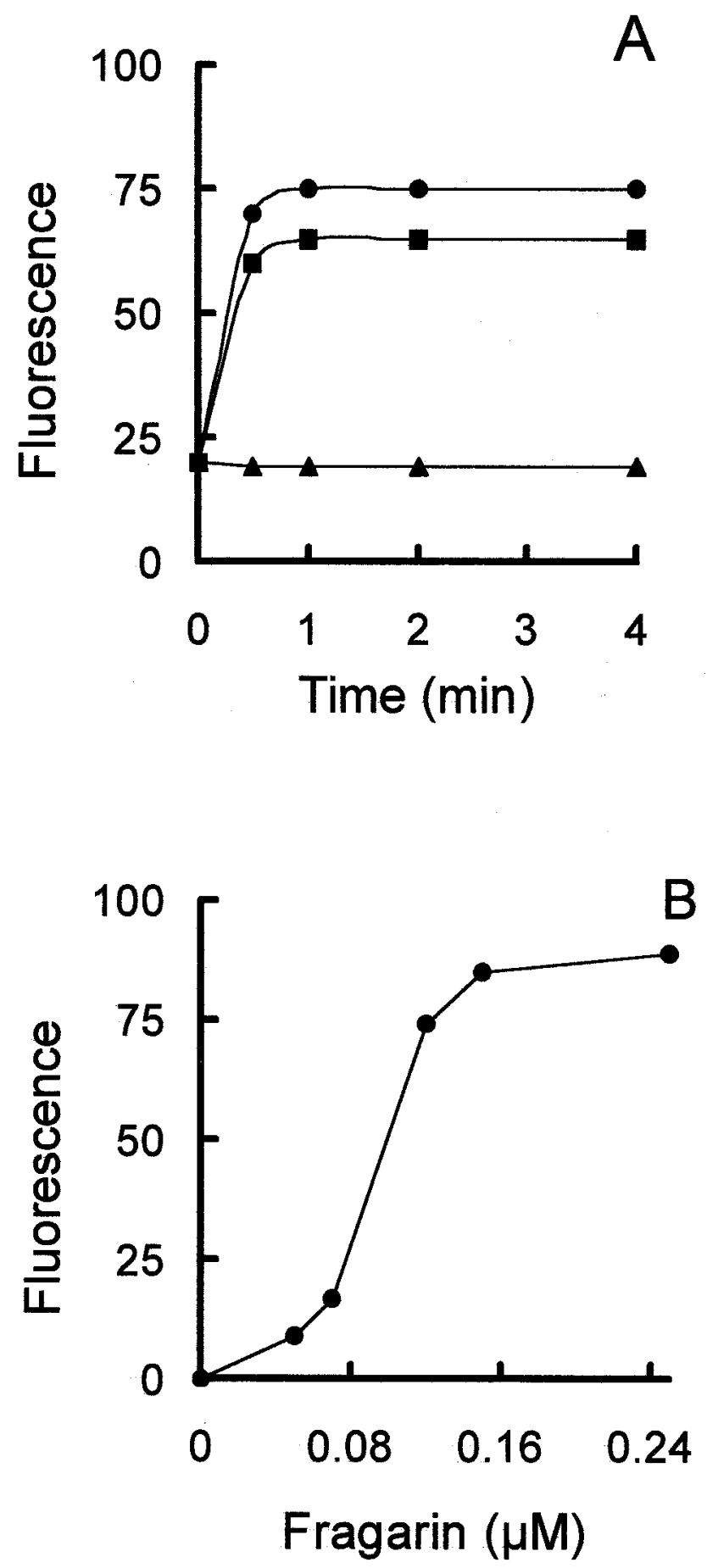

Fig. 3. Fragarin effect on membrane permeability. A, Release of diSC35 from loaded Clavibacter michiganensis cells after the addition of $0.15 \mu \mathrm{M}$ fragarin $(\bullet), 1.0 \mu \mathrm{M}$ valinomycin ( $\mathbf{\bullet})$, and without fragarin or valinomycin addition (A). B, Dose response of fragarin effect on membrane permeability. 


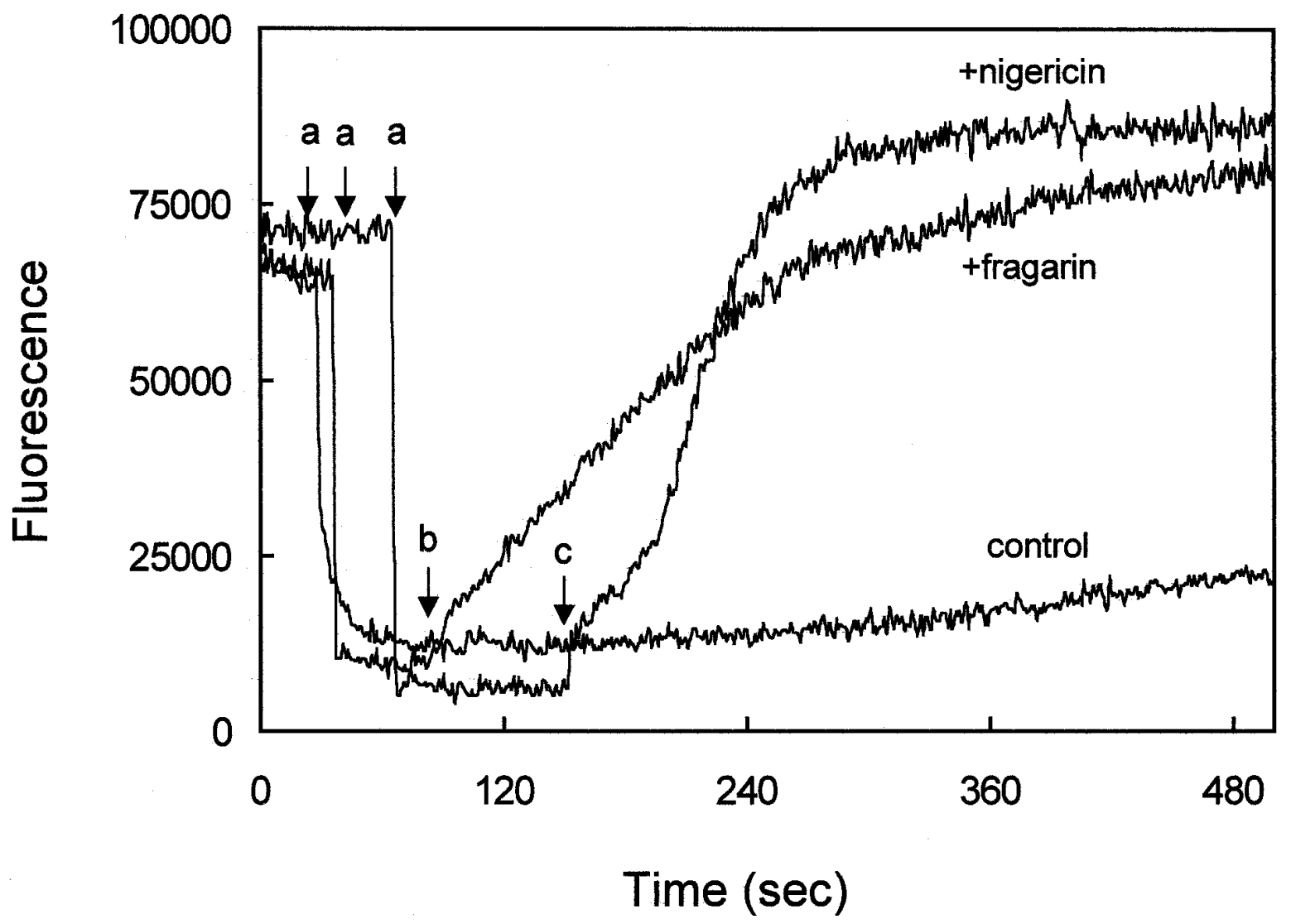

Fig. 4. Effect of fragarin on liposome membrane potential generated by valinomycin. The addition of $0.05 \mu \mathrm{M}$ valinomycin, $0.4 \mu \mathrm{M}$ fragarin, and $1.0 \mu \mathrm{M}$ nigericin are indicated by arrows $\mathrm{a}, \mathrm{b}$, and c, respectively.

effect on the membrane precedes or is simultaneous with cell death (Fig. 1).

\section{ACKNOWLEDGMENTS}

This work was supported partially by Consejo de Investigaciones de la Universidad Nacional de Tucumán (CIUNT); Consejo Nacional de Investigaciones Científicas y Técnicas (CONICET); International Foundation for Science (IFS), Sweden (grant F/2568-1); and Agencia Nacional de Promoción Científica y Tecnológica (PMT/SID No: 552). M. P. Filippone is a fellow and J. C. Diaz-Ricci, A. P. Castagnaro, and R. N. Farías are career members of CONICET.

\section{LITERATURE CITED}

Filippone, M. P., Diaz Ricci, J. C., Mamani de Marchese. A., Farias, R. N., and Castagnaro, A. P. 1999. Isolation and purification of a 316 Da preformed compound from strawberry (Fragaria ananassa) leaves active against plant pathogens. FEBS Lett. 459:115-118.

Gao, F. H., Abbe, T., and Konings, W. N. 1991. Mechanism of action of the peptide antibiotic nisin in liposomes and cytochrome $c$ oxidase containing proteoliposomes. Appl. Environ. Microbiol. 57:2164-2170.

Harbone, J. B. 1991. Bioactive compounds from plants. Pages 126-139 in: Role of Secondary Metabolites in Chemical Defense Mechanisms in Plants. D. J. Chadwik and J. Marsh, eds. John Wiley and Sons, Chichester, U.K.

Kates, M. 1986. Techniques of Lipidology: Isolation, Analysis and Identification of Lipids, 2nd ed. Elsevier Biomedical Press, Amsterdam.

Kuc, J. 1995. Phytoalexins, stress metabolism and disease resistance in plants. Annu. Rev. Phytopathol. 33:275-295.

Osbourn, A. E. 1996. Preformed antimicrobial compounds and plant defense against fungal attack. Plant Cell 8:1821-1831.

Rottenberg H., and Scarpa, A. 1974. Calcium uptake and membrane potential in mitochondria. Biochemistry 13:4811-4817.

Van Etten, H. D., Mansfield, J. W., Bailey, J. A., and Farmer, E. E. 1994 Two classes of plant antibiotics: Phytoalexins versus phytoanticipins. Plant Cell 6:1191-1192.

Wu, M., Maier, E., Benz, R., and Hancock, E. W. 1999. Mechanism of interaction of different classes of cationic antimicrobial peptides with planar bilayers and with the cytoplasmic membrane of Escherichia coli. Biochemistry 38:7235-7242. 